\title{
Adult Education Using the Moodle E-Learning Platform: The Role of the Trainer
}

\author{
Evgenia Pavlakou \\ M.Sc. Marketing and Communication \\ Athens Business School of Economics \\ Education Management \\ Konstantinos Kalachanis \\ $\mathrm{PhD}$ in Philosophy \\ National and Kapodistrian University of Athens \\ Research Fellow NeaGnosi \\ Professional and Vocational \\ Training
}

\begin{abstract}
Distance learning is characterized by the use of technological tools that substitute for the physical presence of either the trainer or trainee and is also widely used in the field of adult education. The main feature of distance learning programs is the use of an asynchronous platform system (Moodle), which promotes learner's critical thinking and creativity by linking learning to practice, reflection, case study and exploration. The trainer, for his part, designs e-courses with the capabilities of using educational material such as videos, presentations, images, etc. In addition, the use of an online platform (Moodle) promotes learner's individualized learning pathway, as well as the ability of participants to interact, principles that are compatible with the critical thinking that governs the principles of adult education.
\end{abstract}

Keywords: Moodle. Trainer.e learning.

\section{Introduction}

The development of new technologies, and in particular the development of the Internet and its applications, had a major impact in learning as well, as the use of the e-learning platform has become established. Especially the Adult Education has implemented its distance learning practices using an online platform that offers many advantages to the teacher and the participants. In the present work we will initially talk about the characteristics of distance learning, and the nits applications in adult education will be studied, focusing on the use of the Moodle electronic platform. Finally, the role of the trainer, which is the factor determining to a large extent the success of the educational process, will be examined.

\section{Distance learning (e learning)}

The traditional form of teaching was characterized by the interpersonal relationship between a pedagogue and another one in which, with the assistance of the teacher, the student developed his / her skills and character, the main means of this interpersonal contact (Kroustalakis, 2002). However, technological progress has been logical to influence the provision of education, as gradual teaching resources are upgraded. It is worth noting that as surveillance means are defined the objects and technological applications (video, TV) that create new sensory channels in order to improve the quality of the educational process. The development of supervisory teaching instruments began with the method of correspondence and printed material. Nowadays the technological evolution has resulted in the use of devices such as video, television and in particular of the Internet thus making communication between the teacher and the student easier (Georgiou \& Kioulanis, 2013, p. 135). Therefore, the educational process is continually utilizing new technologies.

However, the innovation of distance learning is the use of technological tools (computer, television, etc.) that substitute e the physical presence of the trainer and trainee (Kaplan and Haenlein, 2016). However, this does not necessarily mean that the role of the trainer is degraded, but it rather demands much more planning capabilities (Rossi, 2009). 
However, in order for distance learning to be successful, according to the American Distance Education Consortium (http://www.adec.edu), it should serve the achievement of the learning goals but also the individual needs of each learner according to the nature of the training program Finally, the trainee should be encouraged to participate actively in the learning process by combining Learning by Doing, Learning by Reflection, Case-Based Learning, Learning by Exploring. Therefore the proper use of distance learning provides important opportunities for both the trainer and the trainee.

It is also characteristic that this method has been widely adopted by universities throughout the world, as it provides significant facilities for students (Chow \& Croxton, 2017). It is therefore necessary to familiarize both trainees and trainers (Fischer et al. 2015) so that all levels of education are now adapted to the new reality of distance learning.

\section{The implementation of the electronic platform in Adult Education}

Developments in the field of economy and society, as well as scientific progress, particularly in the fields related to technology, have made it necessary to acquire skills (foreign languages, use of computers, etc.), which in many cases are not covered by the formal education (primary, secondary and tertiary). In this context, Adult Education, a branch of Lifelong Learning, helps adults to acquire new skills in order to broaden their spiritual horizons or to acquire additional skills for their workplace. It is worth noting that well reputed universities and educational institutions have adopted strategies with academic frameworks including innovative pedagogical approaches which appeal to modern lifelong learning systems (Chiţiba, 2012).

Specifically through Adult Education:

a) New opportunities for employment and social inclusion are offered to the individual. Taking into account the increased labor competition and social subsidence, modern man has to integrate lifelong learning into his life.

b) The individual's personality develops in a knowledge and information society and acquires the capacity to manage knowledge and therefore can actively respond to the professional and social challenges of modern reality. c) Adult education includes the improvement and development of skills already acquired in order to be able to keep pace with current job requirements and the acquisition of new skills and knowledge stemming from new economic data and latest developments in science and technology (Dann-Messier, 2011). So, due to the new requirements in the labor market where workers need to adapt to fit changing roles, "learning to learn" is therefore a crucial skill for the trainees (Bridgestock, 2014).

It is evident from the above that adult education is largely aimed at people who for various reasons have not been able to show their abilities in the education system (Kokkos, 2005, p.176), thus essentially have a second chance to improve the cognitive background. This is where new technologies, especially distance learning, have the advantage of significant time savings, as well as the provision of educational programs according to the needs and interests of citizens. Besides, many adults who are employed exploit the fact that they have access without geographical or temporal obstacles.

Distance Adult Education takes place using tele-education systems, commonly known as "platforms", and includes a variety of course management tools, access tools to educational material resources and both synchronous and asynchronous communication means. In particular, the advantages of using an asynchronous tele-learning platform are summarized in the following: (Ministry of National Education and Religious Affairs, 2006, p. 25).

- Ease of access to educational material through web pages.

- Support for the integration of multimedia information through image, audio and video files.

- Asynchronous communication through services such as e-mail, bulletin boards and discussion groups.

- Contemporary communication through services such as chat and video-conference teleconferencing.

- Support the learning process through tools to monitor student progress, search for self-assessment information and activities.

- Management of the course through recording management tools, on-line scoring and collection and grading of learners' assignments.

- Help desk to support the trainer and trainee to provide facilities and answer questions.

One of the most popular platforms is the Model (Modular Object-Oriented Dynamic Learning Environment) defined as (Moodle: Retrieved from: https://el.wikipedia.org/wiki/Moodle) (Figure 1): 

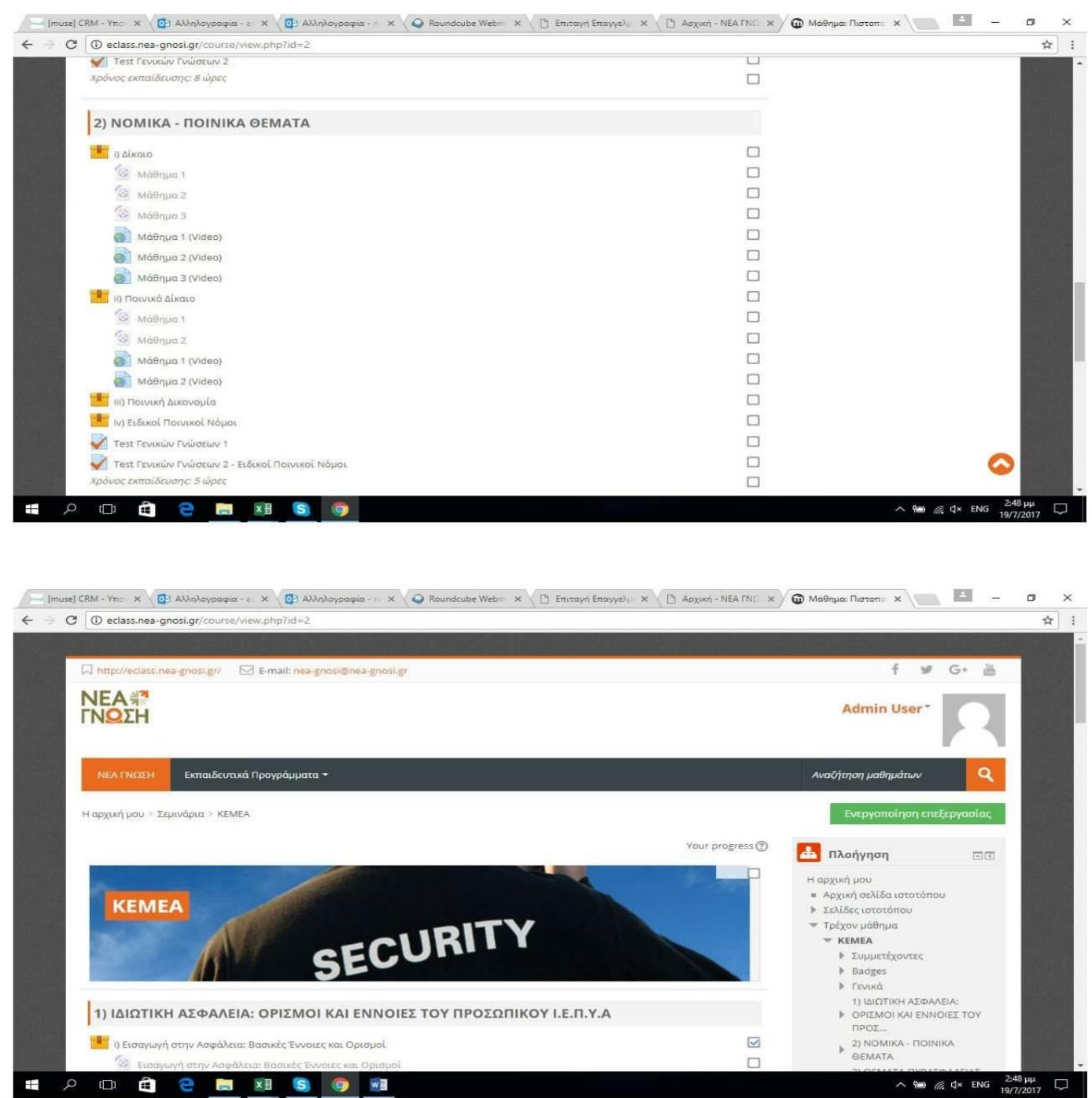

Figure 1: Moodle-based e-learning platform image used by NeaGnosi, Professional and Vocational Training. Moodle provides the trainee with the ability of navigation, but it also allows to upload files in various formats (doc, pdf, jpeg) and videos.

- Learning Management System (LMS)

- Virtual Learning Environment (VLE)

- As a software package for online e-learning, offering integrated asynchronous e-learning services.

\section{The role of the trainer}

A catalyst for the success of the educational project in distance learning is the trainer, who will undertake the task of implementing the training program. The successful use of learning platforms in the teaching and learning context depends primarily on the skills and knowledge of the teacher who should be capable of organizing all the communication process (Costa et al. 2012). It should be clarified here that the traditional process of learning, especially in formal education (primary, secondary and tertiary), proposes the presence of both the teaching and the teaching manual as the primary "sources" of knowledge communicated to students by the use of teaching resources to have a supportive role. On the contrary, it is argued that distance learning removes the trainer from the learning center, as his role is limited by the lecturer in organizing and developing knowledge (Cohen \& Malgorzata, 2006, p. 26).

However, the role of the trainer is not simply to adapt and implement a program aimed at the traditional class, but to upgrade the educational process and respond to the needs of his/her students. Indeed the working environment provided by Moodle platform has the advantage of making the teachers "equal partners in the development" while at the same time they can make any adjustments they need (Kotzer \& Elran, 2012). 
It is obvious that one main advantage of these environments is the freedom of teachers to add, change or use them as is, according to their needs.

In reality, however, the role of the trainer - even when the learning process takes place remotely - is still vital, as he is now responsible for designing and managing e-courses. The trainer through technology applications (video, presentations, etc.) has to activate the learner in a heuristic course towards knowledge (see Vouzaxakis \& Georgiadis, 2013), which will be interesting for them. But in order to be successful, he must have the following skills:

- Ability to know the appropriate scientific resources that are accessible, particularly via the Internet. This involves the training of the trainer, who should be aware of the subject.

- Flexibility to modify his / her material if required by the educational objectives and the needs of the participants.

- Interaction so that the lesson does not make them lose interest, but also promotes interaction between the participants. The trainer can also use applications like skype, messenger, etc. so that he can be in direct contact with the participants. In addition, e-Learning platforms also provide the opportunity to create a forum for exchange of views among trainees.

- The course is personalized for each participant and effectively meets his / her needs.

Apart from the design of the lesson and the means to be used, the trainer has to activate the adult to achieve the goal of self-realization. In fact, according to the theory of And ragogy, learning is by definition a process where adult experiences are constantly transformed and influenced by experiences, with the trainer teaching the adult how to learn (see Knowles 1978 at the Ministry of National Education and Religious Affairs, 2006, p. 27). Distance education also contributes to the process of transformative learning as it promotes the learner-centered perspective, the knowledge-centered perspective, and the community-centered perspective, (Forrester, 2006). Moreover, the concept of transforming learning is correlated with the selectively shaping of our expectations, perceptions, cognition, and feelings with the consequence of actually defining our attitude of life, but also of changing perceptions (Mezirow, 1997).

Consequently the trainer when designing an e-learning platform should take into account that adults have totally different requirements compared to students, a fact that makes the trainer's job difficult. The fact that adults have established beliefs and in many cases do not respond positively to learning new things is considered as a major drawback in the learning process (Roosma\& Saar, 2016). In particular, an adult needs to know why he should learn and should also have the opportunity to make choices about his life. In addition, adults are influenced by their experiences, but also by the abundance of experiences, which differentiates them from students. Finally, the design of the courses by the trainer should not be oriented around the provision of academic knowledge but should cover the trainee's practical needs (see, in particular, Kokkos, 2005, pp. 48-49) that will be used in his working environment. At the same time, the trainer should be able to overcome any difficulties created by distance learning. It is mentioned that many adults may feel anxious and underachieving in their attempt to keep up with the learning program. Factors such as financial cost, lack of family support hopelessness and irrelevance of their education material may have an adverse effect in the effort of the adult to enrich his / her skills through a distance learning program (Pozdnyakova \& Pozdnyakov, 2017). In particular, it sometimes takes more time to prepare its modules, and it should also address the lack of ability of some learners to become acquainted with the use of new technology, which can even create anxiety (Dongsong et al. 2004). Therefore, the online platform should be easy to use so that learners and trainers can make the most of their capabilities. Despite the advantages of e-Learning platforms, it should be mentioned that a large number of trainees prefer the traditional teaching method and particularly lecture style classes (Johnson \& Dasgupta, 2005).

It is evident from the above that the role of the trainer using an electronic platform is to design and manage the ecourse and to help the adult achieve his or her goals.

\section{Conclusion}

From the above, it is clear that the use of an online platform in Adult Education, in particular Moodle, provides many advantages to the teacher and improves his / her educational work while responding to the individual needs of learners. The trainer, for his part, should have the appropriate skills not only to organize his / her educational unit but also to maintain the interest of the participants. 
The learner's individualized learning pathway is also sought, as well as the ability of the participants to interact, from which the use of an electronic platform (Moodle) is a parameter that is compatible with the critical thinking that governs the principles of adult education.

\section{References}

Bridgestock, L. (2014). The importance of learning to learn. [Online] Available:www.topun iversities.co $\mathrm{m} / \mathrm{blog}$ /importance-learning-learn (accessed 5 September 2015).

Chiţiba, C. A. (2012). Lifelong Learning Challenges and Opportunities for Traditional Universities. Procedia Social and Behavioral Sciences Volume 46, 2012, 1943-1947.

Chow, A. \&Croxton, R. A. (2017).Designing a Responsive e-LearningInfrastructure: Systemic Change in Higher Education. American Journal of Distance Education, 1-21.

Cohen, E. B., \&Malgorzata, N. (2006). Learning Objects and E-Learning: an Informing Science Perspective. Interdisciplinary Journal of Knowledge and Learning Objects. Volume 2, 23-34.

Costa, C., Alvelos, H., \& Teixeira, L. (2012). The use of Moodle e-learning platform: a study in a Portuguese University. Procedia Technology 5334 - 343.Dongsong, Z., Zhao, L., Zhou, L., \&Nunamaker, J. F. Jr. (2004). Can e-learning replace classroom learning? Communications of the ACM Volume 47, Number 5 75-79.

Forrester, G. Motteram, G. Bangxiang, L. (2006). Transforming Chinese teachers' thinking, learning and understanding via e-learning.Journal of Education for Teaching, Vol. 32, Issue 2.

Georgiou, A., \&Kioulanis, S. (2013). Applying the creative method learning "The Six Hats of Thought" in adult education through web-based distance teacher training".Scientific Educational Magazine. Ekpaideutik osKyklos vol. 1, issue 3 (in greek).

Hirschel, R. (2012). Moodle: Students' perspectives on forums, glossaries and Quizzes. Jalt Call Journal, Vol. 8, No.2 95-112.

Johnson, H.D., \&Dasgupta, N. (2017). Traditional versus Non-traditional Teaching: Perspectives of Students in Introductory Statistics Classes. Journal of Statistics Education, 13:2.

Kaplan, A. M., Haenlein, M. (2016). Higher education and the digital revolution: About MOOCs, SPOCs, social media, and the Cookie Monster. Business Horizons, vol. 59, issue 4, pages 441-450.

Knowles, M. S. (1978). The adult learner: A neglected species (2nd ed.). Houston, TX: Gulf.

Kokkos, A. (2005). Adult Education: Detecting the field. Athens: Metechmio Publications, (in greek).

Kotzer, S. \&Elran, Y. (2012). Learning and teaching with Moodle-based E-learning environments, combining learning skills and content in the fields of Math and Science \& Technology. Proceedings of 1st Moodle Research Conference Heraklion, Crete-Greece September, 14 - 15, 122-131.

Kroustallakis, G. (2002). Education: A lifetime route. Athens: self-edited (in greek).

Moodle.(https://el.wikipedia.org/wiki/Moodle Last Modified May 7th 2017.

Martín-Blas, T. Serrano-Fernández, A. (2009). The role of new technologies in the learning process: Moodle as a teaching tool in Physics. Computers \&Education, Volume 52, Issue 1, January, 35-44.

Mezirow, J. (1997). Transformative Learning: Theory to Practice. New Directions for Adult \& Continuing Education, Volume 1997, Issue 74,5-12.

Ministry of National Education and Religious Affairs.(2006). Adult education 8.istance Learning in Adult Education -Examples and cases of application. Athens: (in greek).

Pozdnyakova, O. \&Pozdnyakov, A. (2017).Adult Students' Problems in the Distance Learning. Procedia Engineering Volume 178, 243-248.

Rossi, A. (2009). Learning Environment With Elements Of Artificial Intelligence. Journal of e-Learning and Knowledge Society, Vol.5, n.1, $191-199$.

Roosma, E-L., \& Saar, E. (2016). Adults who do not want to participate in learning: a cross-national European analysis of their perceived barriers.International Journal of Lifelong Education, Volume 36, 2017, Issue 3.

Vouzaxakis, G. \&Georgiadis, E. (2013).Using Moodle as a tool for the distance learning of Secondary Teachers Education of Crete. I 7th International Conference in Open \& Distance Learning - November 2013, Athens, Greece - Proceedings (in greek). 